\title{
Handwriting: A Matter of Affairs
}

\author{
Iman M. M. Muwafaq Al-Ghabra ${ }^{1}$ \\ ${ }^{1}$ English Department, College of Education for Women, Baghdad University, Baghdad, Iraq \\ Correspondence: Iman M. M. Muwafaq Al-Ghabra, English Department, College of Education for Women, \\ Baghdad University, Baghdad, Iraq. E-mail: imanmuf@gmail.com
}

Received: August 25, $2015 \quad$ Accepted: September 24, $2015 \quad$ Online Published: September 25, 2015
doi:10.5539/elt.v8n10p168

\begin{abstract}
Academic performance is the main concern of educators all over the world. Authentic researchers have studied the importance of handwriting for improving students' performance, and they have proved that using the hand in writing activates many regions in the brain that are related to memory and comprehension. The study aims at displaying the results of some substantial resources on handwriting to show this importance and its impact on students' academic performance. It also aims at being a loud call for the Ministry of Education, and the Ministry of Higher Education and Scientific Research to make a remedial action through establishing awareness campaigns to show the importance and necessity of updating curriculum to focus on using handwriting to enhance and support the students' reception of information. In order to achieve the success of the mentioned efforts, the researcher refers to training the trainers and establishing writing units that are joined to the learning institutions.
\end{abstract}

Keywords: handwriting, writing, students' reception, academic performance

\section{Introduction}

Writing is the language of culture. People have mostly been known through writing; the old civilizations have been known through their different kinds of writing. Allah "Subhanahu wa Taala" describes His Majesty in the Holly Quran as "the One who taught by pen" in Surat Al-Alaq: 4.Although writing is the fourth skill, yet it is the most important one:

1) Listening: It is the first skill that a man experiences to know things and store them. Being a good listener, one must be patient.

2) Speaking: It is the skill of producing and using what have been stored. Being a good speaker, one must be a good listener and reader.

3) Reading: It is the third skill. Being a good reader, one must continue reading to understand the different forms of writing.

4) Writing: It is the fourth skill. Being a good writer, one must continue listening, reading and writing.

No one can argue that there is no relation between hand and brain. Lundborg (2003) states that "the hand shapes the mind in functional terms - we should rather regard the brain as an extension of the hand into our mind exploring and revealing the secrets of the surrounding world." Hence, using hands in writing is a kind of challenge. It is said that cells in the brain become larger when they face stronger challenges; this enhances intelligence.

Using smart machines has decreased the chances of using hands in general and handwriting in particular. In the past, teachers used to teach multiplying tables by asking students to write each table more than 30 times; they repeat this process at the beginning of each academic year till they become sure that students have memorized them. Therefore, people of that age, even if they have not accessed high studies, are better in such mathematical operations more than many of modern age people even if they have accessed higher education because of their entire dependence on calculators. Unfortunately nowadays, it appears common to see educated people using calculators to add only two simple figures. They feel dizzy and amazed if they are told the correct result before they see it in the calculator, and they consider such persons have tremendous brains. 
What is said about mathematics can also be said about all other subjects. At the elementary stages, pupils were asked to write each subject at least twice. There was an hour a week dedicated for "dictation" and feedback. Pupils were asked to repeat writing the corrected words for at least 10 times. Many years have passed since focusing on handwriting has faded away; this has had its effect on both the learners' performance as students and their efficiency as teachers.

Being perfect in any skill cannot be achieved without spending daily hours on continuous practice. Using computer programs may play as helping aids to support learning, but they do not substitute the real training to build professional skills. Like footballers and musicians need continual practice to be skilled, writers need. Gladwell (2011) tells about the story of outliers' success; he assures that researchers have found that training for 10000 hours makes experts and professionals. More than ten thousand hours training may be gained simultaneously along with studying during the whole years of the different learning stages.

According to the researcher's experience as a writing teacher, she supposes that the years of training children on handwriting through the elementary and intermediate study are so important because they are the years of building strong foundation for good writing and academic performance. Appendices 1 and 2 show the poor writing products of students after spending (15) years of study; this is strong evidence that those students have not experienced training well enough on writing in general, nor on handwriting in particular. These writing products are taken from $2^{\text {nd }}$ university level students' products, English department, College of Education for Women, Baghdad University of the year 2014 - 2015.

\section{Problem of the Study}

Unfortunately, the handwriting decay started since the emergence of photocopier machines. Quitting handwriting is not a specific problem for English as a foreign language; it is a generic problem concerning all the different fields of teaching and learning - including the native language. It became clear that the focus on handwriting had died away through all the study years in spite of its great importance. Exam questions and their answers are evident to show that there is no focus on writing; most questions are objective even those of the public exams. The spread of technology gave a logic reason for teachers and students to quit handwriting; they became machine dependents that they cannot make resolutions without using any. Hence, the teaching process does not encourage students to write, and this leads to the decay of their academic performance.

Since writing well needs a certain level of fluency in using suitable vocabulary, structure and organization of ideas, the researcher attracts the attention to the importance of executing a similar study to the one of Montgomery (2008) who points out the necessity of watching the students' speed of writing and the number of spelling mistakes in order to do well in their studies. The study shows that English students at the age of eleven must have the ability to write 25 words per minute and must not commit more than five spelling mistakes in each 100 words. In her research, Montgomery finds that one third of children of three suburban secondary schools whose ages range (11-12) do not meet the criterion of spelling. In addition, more than $95 \%$ of the same sample does not meet the criterion of handwriting speed.

Students' performance in general and writing in particular has become the main concern in most of the countries because they have grown weaker over time. Despite the serious attempts through using different innovative teaching programs, educators could not move the majority of pupils and students to be good enough in reading and writing to meet the demands of their real levels. This may be due to the fact of neglecting handwriting which is one of the most important aspects of the academic learning process. The researcher supposes that the real problem is that the machine became smarter than humans who do not know the basics of literate life without using at least one machine.

Three amazing questions have often been raised:

a. What is the best resolution to overcome this problem in the age of speed and technology?

b. What will one do if for some reason the machine does not work?

c. What is the best method to support students' academic performance?

\section{Significance of the Study}

Many authors consider handwriting important in spite of the technological dominance, especially, in the primary stages of learning. Clark (2010) states that the World Health Organization's 2002 has highlighted the value of writing, and considered writing difficulties as a real impediment to school participation. Preparing better writers 
requires more concern on handwriting skills which are critical for future success.

Graham and Herbert (2010) present an evidence showing how writing, in general, can improve reading, and they display the close relationship between writing and comprehension in all the different subjects. The benefit of handwriting can be invested to implant the basics of academic writing since the elementary stages, so that students can focus only on the information in later stages. Grammar, spelling, punctuation, handwriting, organizing ideas and arrangement of writing are the basics of academic writing as multiplying tables are the basics of mathematic operations. Thus, all these basics should be focused on by recurrent handwriting assignments from the elementary stages. Hence, students will fully be armed with all basics of academic writing when they join college, and they will be ready to receive and search for information. They will also be able to write notes easily following their professors, summarizing and paraphrasing different kinds of information. Hence, college professors could give broader and more advanced information with less effort.

\section{Aim of the Study}

The researcher hopes that the current study might be of some help for curriculum makers and teachers to revise their plans concerning the focus on handwriting. The study aims at:

a. accessing some of the most useful researches on neuro-psychology and education to pinpoint how handwriting impact on students' performance,

b. displaying the results of those researches in front of educators who are in charge in order to take the necessary steps to solve the mentioned problem.

\section{Previous Literature}

According to the precious readings concerning handwriting and its relation with the learning process, the researcher has been convinced that handwriting activates the brain while technology broadens it.

Raimes (1991) states that since the communicative approach does not encourage interrupting students to correct errors, writing - referring to handwriting - is better for this concern. He focuses on the importance of writing to the learning process since it gives students enough time to think and write, and then correct what they write. In addition, writing is the best situation for teachers to help their students with feedback.

Berninger (2009) confirms that the effect of using a pen is stronger than that of using a keyboard among children. This result is due to her study on $2^{\text {nd }}, 4^{\text {th }}$, and $6^{\text {th }}$ grade children; she notices that they write more and faster when they use a pen.

Medwell et al. (2009): They state that training the hand in writing leads to train the memory as well, so that both of the hand and memory work together in order to produce good writing. They use three kinds of measurement to test their sample which contains (198) pupils from four primary schools. These kinds of measurement are:

- Handwriting SAT (Statutorily assessed as part of the national test).

- Handwriting speed (children are given a sentence to repeat writing it as many as they can within three minutes).

- $\quad$ Alphabet task.

Mangen and Velay (2010) state that there has been strong evidence from neuroscience pointing out the importance of repeated movements of hand in writing for memorizing. Japanese schools use the way of repeating writing by hand to help their children memorize kanji characters. Japanese adults use the same movements in the air to distinguish between complex characters.

FYI Health Writer (2011): Reviews of previous studies opine that the hand is the focal point of the real life success and skilled achievement. They urge educators to modify their teaching according to those results achieved by researchers.

Van der Merwe, Joanne et al. (2011) have done a questionnaire to study how South African occupational therapists treat learners with poor handwriting who are at the fundamental stage. They have found that the following factors which should be assessed impact handwriting:

- handwriting legibility components,

- handwriting speed,

- handwriting domains, 
- ergonomic factors,

- environmental factors,

- intrinsic performance components.

James and Engelhardt (2012) have conducted a study to watch the different degrees of brain activation due to handwriting and typing. It has shown that the activated regions in the brain through handwriting are more than those are activated through typing. This gives prior importance to handwriting for mental letter recognition.

Javed et al. (2013) have carried out their study to evaluate and assess the writing of secondary school level students - grade 10 - focusing on five aspects. Handwriting is one of the five aspects; vocabulary, sentences, comprehension, and tenses are the others.

Peverly et al. (2013) have carried out their study to evaluate handwriting speed as one of a group of factors that have their effect on the performance of college students. The study has uncovered the importance of speedy handwriting for positive quality and quantity fulfillment of different kinds of writing among children and adults.

\section{Fingers Movement and the Reception in the Mind}

No doubt fingers send messages to the mind as they move in writing; the repeated movement of hand in writing helps in memorization. Mangen and Velay (2010) state that in handwriting, the visual attention strongly focuses on the movement of hand while in typing, the visual attention scatters between hitting the keyboard, and watching the screen. Thus, tracing letters is important for children to improve their writing because they can focus only on drawing letters.

Hence, handwriting is better for students than typing to gain more information; this is confirmed by Alleyene (2011). In his article, Alleyene states that handwriting lets the information stick in the brain rather than typing; writing the piece of information is as imprinting it in the brain. In addition, FYI Health Writer (2011) states that since handwriting requires using motor skills which takes some time to copy letters, this process helps children to develop their learning and cognition.

James and Engelhardt (2012) assure that handwriting is important for the mental perception of letters. They have conducted a research on 15 children to see the difference of brain activation during letter perception between the children who experience letter writing and those who experience letter typing. They have presented evidence through MRI scanning that the activated brain regions were more with those who experience writing than those who experience typing; the activated brain regions are concerned with reading and writing.

Thus, using hands in writing enables children to master shaping letters and memorizing words more quickly. Hence, it is important for children to receive feedback in order not to memorize mistaken words. Handwriting will be of no use without continued feedback showing the correct usage of spelling, and gradually advancing towards grammar, punctuation, and afterwards showing how to choose suitable vocabulary to form meaningful sentences and build a cohesive paragraph.

\section{Handwriting, Memory Activating and Information Recalling}

The primary concern of the professional educators is to enhance the student's ability to save knowledge in the brain and retrieve it. Banikowski (1999) refers to the importance of memory for educators because it is the evidence of learning something, and it is the focus of using and remembering the different pieces of information.

Bloom (1987) has assured that the process of learning could be achieved through the active engagement. He has demonstrated different forms of engaging individuals in different activities, and indicated different levels of learning achievement for each activity as in the following:

$10 \%$ of what they READ

$20 \%$ of what they HEAR

$30 \%$ of what they SEE

$50 \%$ of what they SEE \& HEAR

$70 \%$ of what they SAY

$90 \%$ of what they SAY \& DO

For this reason, it is widely common among teachers to advise children to say what they write while they write 
especially at the early stages of learning "SAY \& DO", so that they could save $90 \%$ of the information.

Medwell et al. (2007) state that the process of handwriting is a process of training the hand to work with the memory to retrieve the suitable mental images, so that one can write automatically and effortlessly. Automaticity helps the memory not to be overloaded. This cannot be achieved unless one continues training to write swiftly.

This is supported by the neuro-scientific study of Longcamp et al. (2008) which evaluates the ability of adults' recognition after being trained to recognize new characters using either handwriting with pen and paper or typing with computer keyboard. Results have revealed that recognizing the written characters with pen and paper have lasted in memory more than the typed ones. They contribute the reason of those results to the activation of several regions in the brain which are responsible for observing and recognizing during writing with pen and paper rather than during typing with computer.

Two years later, Virginia Berninger, the professor of educational psychology at the University of Washington (2010) got the same results. Referring to pictures showing the activation of massive regions of thinking, language and working memory due to sequential finger movements while writing which differ from pictures taken while typing to form a letter, Berninger states that the mentioned regions are not affected while typing because it does not require more than touching the right key; on the contrary, writing requires more effect using sequential strokes.

\section{Handwriting and the Students' Academic Performance}

The breakthrough in technology has lead teachers to get away from the focus on handwriting in spite of the declaration of its necessity by communicative approach supporters. Raimes (1991) states that since the communicative approach does not support the idea of interrupting pupils in order to correct their errors, writing -the whole article refers to writing by hand- shows the exact words of their speech, and it is the best way to correct the pupils' language production through giving them feedback, so that teachers could show them their grammatical and rhetorical mistakes. Hence, pupils could follow up their mistakes, correct them and improve themselves.

The focus on writing has become so poor to the extent that pupils have gradually begun to lose this important skill. The use of correction software programs in the early stages has its negative effect on the learning process because it forbids learners from thinking and recognizing the distinction between the wrong and right. Handwriting is one of the fine motors which involve using the hands and fingers. It requires the small hand muscles to work altogether in order that they could perform precise and refined movements.

Longcamp et al. (2005) confirm that hand movements have their considerable role in drawing letters, and they suggest that handwriting helps the visual recognition of letters. They have conducted a study on 76 children, at the age of preschool, to watch if there is any effect on teaching children how to type letters before writing them on their perceiving the written language. The children were grouped into two; one of the groups was trained on typing; the other was trained on handwriting. The correct results of the handwriting group have shown significance in regard to those of the typing group.

Tennyson (2006) mentions many authors (Amundson, 2001; Berninger et al., 1997; Levine, 1994; Van Galen, 1991; Weintraub \& Graham, 2000) who have reported that handwriting is considered a complex process because it involves more than one process at the same time: "synthesis of cognition, visual perception, motor skill, integration of memory, problem solving, organization, reading and language ability, ideation, and grapho-motor function." Hence, since practicing writing involves all the mentioned processes together, it could be considered a type of training to creativity which requires divergent thinking.

Van (2011) states that intrinsic and extrinsic factors cause handwriting weakness. Officials should thoughtfully study those impacting factors on handwriting to consider them in designing a remedial program. The remedial program must focus on quality which is fulfilled by legibility, and quantity which is fulfilled by speed.

In PR Newswire (2012), experts of the educational summit which was held in Washington, confirm on the importance of handwriting to the development of students' learning and success, and thus, they agree upon the necessity of staying handwriting and cursive in the curriculum. Attendees have been convinced through presentations and workshops that handwriting helps children in different areas of learning. The summit's survey has shown that $85 \%$ of 150 attendees voiced for the importance of teaching handwriting during the elementary years. 
None can overlook the importance of note-taking to raise the students' performance level; most of students depend on their note-taking when they prepare for exams. Peverly et al. (2013) refer to the importance of speedy handwriting for taking notes which are considered an effective aid for the personal memory. Since the information is usually quickly forgotten, note-takers need to write it quickly before it is forgotten. Thus, teachers must put the speed of writing in their consideration when they teach and assess writing.

\section{The Researcher's Lesson Plan Sample}

The researcher proposes that writing and rewriting is a vital tool for students to improve the content and accuracy of their writing. Handwriting is better than typing because handwriting reveals the exact position of weakness while in typing, grammar and spelling mistakes may be corrected by a software program, and the writer does not know how and why they are written so.

Although the basics of writing are not the prime concern of college professors in teaching students writing, the researcher found herself that she cannot progress without focusing on the details of the simplest rules because of the weakness of the majority of students in writing. The researcher got benefit from the previous literature and adopted the following method with her $2^{\text {nd }}$ year university level students to write well and improve their writing. The method adopted focused on the following aspects:

Time: The weekly two-hour lecture was divided into three thirds.

The first part was dedicated for explaining one aspect of writing, and showing students a sample in order to be ready for doing assignments.

The second part was dedicated for letting the students write a paragraph.

The third part was dedicated for speedy checking and giving feedback.

Assignments: Students were asked to write a paragraph on a certain topic as a first draft, ask and answer questions, and then rewrite the final copy. The focus was always on grammar, spelling, punctuation, ideas, handwriting and arrangement.

Feedback: The researcher wandered among students during their writing to check the common mistakes. Finishing their time of writing, the researcher collected 4-5 papers to comment on some of the common mistakes; then she chose the best sample, reviewed it in front of the students and asked them to correct and improve their writing accordingly.

\section{Conclusion}

Different educational and neuro-scientific researches on handwriting have shown that it has its real impact on memory activation and information recalling due to fingers movement. They have also confirmed that handwriting let the information stick in the brain and last more time than typing.

Medwell et al. (2009: 330) state that automaticity of handwriting is important in order not to occupy any space in the individual's memory. Hence, when writing, children can focus on the information rather than the process of writing. This cannot be achieved unless they can write swiftly and effortlessly. Therefore, teachers must dedicate hours a day to let children be trained on writing, and given feedback.

The researcher supports the idea of the impact of intrinsic and extrinsic motives on handwriting and then on academic performance; the researcher has tried to provide the latter, but the first depends on the learners themselves. Only few of the students who have actively responded to improve their writing performance by continuous handwriting training have got clear progress in their writing. Attached appendices show different samples of writing of two different students; three samples for each student. Although both these students show weakness in their writing, yet the first one seems that she has a strong intrinsic motive to improve herself while the second one does not seem that she has the same intrinsic motive in spite of their exposure to the same extrinsic motives.

In conclusion, it is noteworthy that training on the basics of calligraphy should be from the stage of kindergarten. Gladwell (2011) has assured that researchers have found that training for 10000 hours makes experts and professionals. Hence, children should start from kindergartens in order to be ready to receive the information at the stage of elementary teaching. This is important before directing them to use technology. Handwriting is effective to work students' minds; technology is effective to broaden their minds and move them towards creative writing. 


\section{Recommendations:}

Berninger (2012) confirms in her research that handwriting saves ordered alphabet series in the long-term memory. In this respect, it is important that teachers of kindergartens concentrate on teaching children how to grasp pencils correctly in order that they become able to learn the correct way of drawing letters and forming legible handwriting. They must urge their pupils to practice the correct direction of writing letters in order to be readable and pretty. Thus, the role of kindergarten teachers is necessary to involve children in continuous handwriting training programs to prepare them to write effortlessly.

When children become older and move to the next stage of elementary learning, they must have learnt how to write the lowercase and uppercase letters; they must be ready to receive the information. Teachers of this stage must develop children's automaticity of handwriting through challenge and encouragement.

As learners, everyone knows that the active engagement in the process of learning helps the information stick; this goes with what Bloomfield referred to as " $90 \%$ of what they SAY \& DO" concerning the achievement of the learning process. Acquainted with the benefits of handwriting, educators who are in charge of revising and designing curriculum could also put in their consideration the importance of investing 10000 hours of the different stages of teaching in training children and students on academic writing through handwriting.

When pupils commit some kind of spelling mistake in writing words, teachers must not overlook them; they must ask children to repeat the correct form of the mistaken words as many times as they could. Then, teachers must train pupils to put words in meaningful sentences through extra writing assignments; they must ask children to repeat each assignment twice at least. There must be scores to estimate the pupils' abilities in orthography and calligraphy in addition to the correct structure. To achieve this aim, the researcher recommends the following:

Taking serious steps promptly by officials in charge in the Ministries of Education, and Higher Education and Scientific Research in order to investigate the real reasons behind the weakness of academic performance in general and writing in particular,

Launching awareness campaigns in schools and colleges concentrating on the benefit of handwriting,

Training the trainers: Teachers should continuously receive effective and developmental training to be acquainted with the most recent and effective strategies of teaching,

Calling out officials of universities to establish centers for writing to improve the students' writing before graduation,

Establishing writing units in schools for non-class activities,

Counting mainly on writing when choosing qualified teachers,

Setting up a writing assessment system for each educational stage,

Monitoring the teachers' questions of the different stages,

Extending the daily school time at least 2 hours in order to dedicate more effort and time for concentrating on writing assignments and improving academic achievement,

and revising the curriculum to make writing its centerpiece.

\section{Suggestions}

In the light of the benefits of handwriting, it is highly suggested to execute researches to study:

The average speed of students' writing in the different stages of learning and the accepted number of mistakes accordingly,

Other effective strategies of teaching writing to move students towards creative writing,

The suitable time and method for directing students to get benefit from technology to enhance their information.

\section{References}

Alleyen, R. (2011). Write It; don't Type It If You Want Knowledge to Stick, The Telegraph. Retrieved from http://www.telegraph.co.uk/education/educationnews/8271656/Write-it-dont-type-it-if-you-want-knowledg e-to-stick.html

Banikowski, A. K. (1999). Strategies to Enhance Memory Based on Brain-research, Focus on Exceptional Children, 32(2). 
Berninger, V., \& Schwarz, J. (2009). The Pen may be Mighter than the Keyboard, UW Today, University of $\begin{array}{lllll}\text { Washington, } & \text { Retrieved } & \text { September } & 16, & 2009\end{array}$ http://www.washington.edu/news/2009/09/16/the-pen-may-be-mightier-than-the-keyboard/

Berninger, V., \& Bounds, G. (2010). How Handwriting Trains the Brain. The Wall Street Journal.

Berninger, V. (2012) Strengthening the Mind's Eye, Principal. Retrieved May/June 2012, from http://www.azed.gov/special-education/files/2014/05/f2.9-article-minds-eye-handwriting.pdf

Bloom in B., \& Alison, K. (1999). Strategies to Enhance Memory Based on Brain-research. Focus on Exceptional Children, 32(2).

Clark, G. J. (2010). The Relationship between Handwriting, Reading, Fine-motor and Visual-motor Skills in Kindergarteners, a PHD dissertation, Iowa State University, USA.

FYI Health Writer. (2011). Handwriting is Beneficial to Children's Cognitive Development. FYI Living, Retrieved from http://fyiliving.com/research/handwriting-is-beneficial-to-childrens-cognitive-development/

Gladwell, M. (2011). Outliers: The Story of Success, Hachette Book Company, New York.

Graham, S., \& Hebert, M. (2010). Writing to Read: Evidence for How Writing can Improve Reading, Carnegie Corporation of New York.

James, K. H., \& Engelhardt, L. (2012). The Effects of Handwriting Experience on Functional Brain Development in Preliterate Children. Trends in Neuroscience and Education, 1(1), 32-42. http://dx.doi.org/10.1016/j.tine.2012.08.001

Javed, M., Juan, W. X., \& Nazli, S. (2013). A Study of Students' Assessment in Writing Skills of the English Language. International Journal of Instruction, 6(2), 1308-1470.

Ljiljana, B. (2011). Difference of Motor Skills Development between One Grade School Children Assessed by Janda's Methods and ABC-Movement Methods, Palacky University in Olomouc, Czech Republic.

Longcamp, M. (2005). The influence of writing practice on letter recognition in preschool children: A comparison between handwriting and typing. Acta Psychologica, 119, 67-79. http://dx.doi.org/10.1016/j.actpsy.2004.10.019

Longcamp, M. (2008). Learning through Hand- or Typewriting Influences Visual Recognition of New Graphic Shapes: Behavioral and Functional Imaging Evidence. Journal of Cognitive Neuroscience, 20(5), 802-815. http://dx.doi.org/10.1162/jocn.2008.20504

Lundborg, G. (2003). The Hand and the Brain. Rev Med Univ, 47, 7-11.

Mangen, A., \& Velay, J-L. (2010). Digitizing Literacy: reflections on the haptics of writing. Advances in Haptics, Retrieved from http://www.intechopen.com/books/advances-in-haptics/digitizing-literacy-reflections-on-the-haptics-of-writ ing

Medwell, J., Strand, S., \& David, W. (2007). The role of handwriting in composing for Y2 children, Journal of Reading, Writing and Literacy, 2(1), 11-21.

Medwell, J., Strand, S., \& David, W. (2009). The links between handwriting and composing for Y6 children, Cambridge Journal of Education, 39(3), 329-344. http://dx.doi.org/10.1080/03057640903103728

Montgomery, D. (2008). Writing and the National Literacy Strategy. Journal Compilation, NASEN, Blackwell Publishing, UK \& USA.

Peverly, S. T. (2013). The Relationship of Handwriting Speed, Working Memory, Language Comprehension and Outlines to Lecture Note-taking and Test-taking among College Students. Journal of Applied Cognitive Psychology, 27, 115-126. http://dx.doi.org/10.1002/acp.2881

PR Newswire. (2012). Researchers Discuss Impact of Handwriting Instruction on Children. Handwriting Educational Summit in Washington D.C., Retrieved from http://www.prnewswire.com/news-releases/researchers-discuss-impact-of-handwriting-instruction-on-childr en-at-handwriting-educational-summit-in-washington-dc-138125288.html

Raimes, A. (1991). Errors: Windows into the Mind. College ESL, 3(2). 
Tennyson, J. (2006). Effective Occupational Therapy Intervention for Handwriting/Fine Motor Difficulties, A project presented to the Faculty of Humboldt State University in partial fulfillment of the requirements for the degree Master of Art in Education, California, USA.

Van der Merwe, J. (2011). A Survey to Investigate How South African Occupational Therapists in Private Practice are Assessing and Treating Poor Handwriting in Foundation Phase Learners: Part 1 Demographics and Assessment Practices. South African Journal, 41(3).

Appendix 1. Samples of a $2^{\text {nd }}$ year university level student performance, English Department 2014-2015

Test 1 . After a month of introductory studying and training

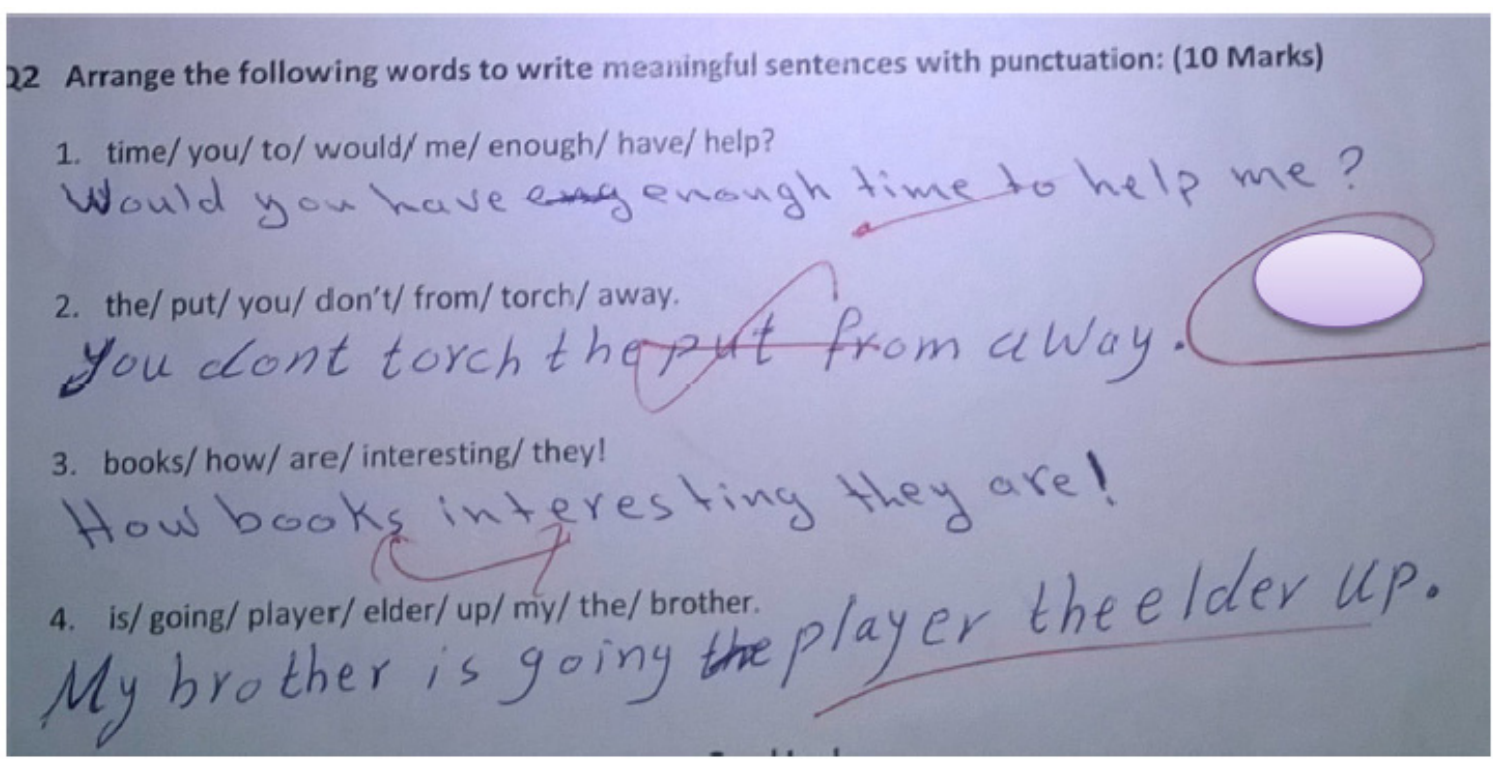

Test 2. Three months later than the first one

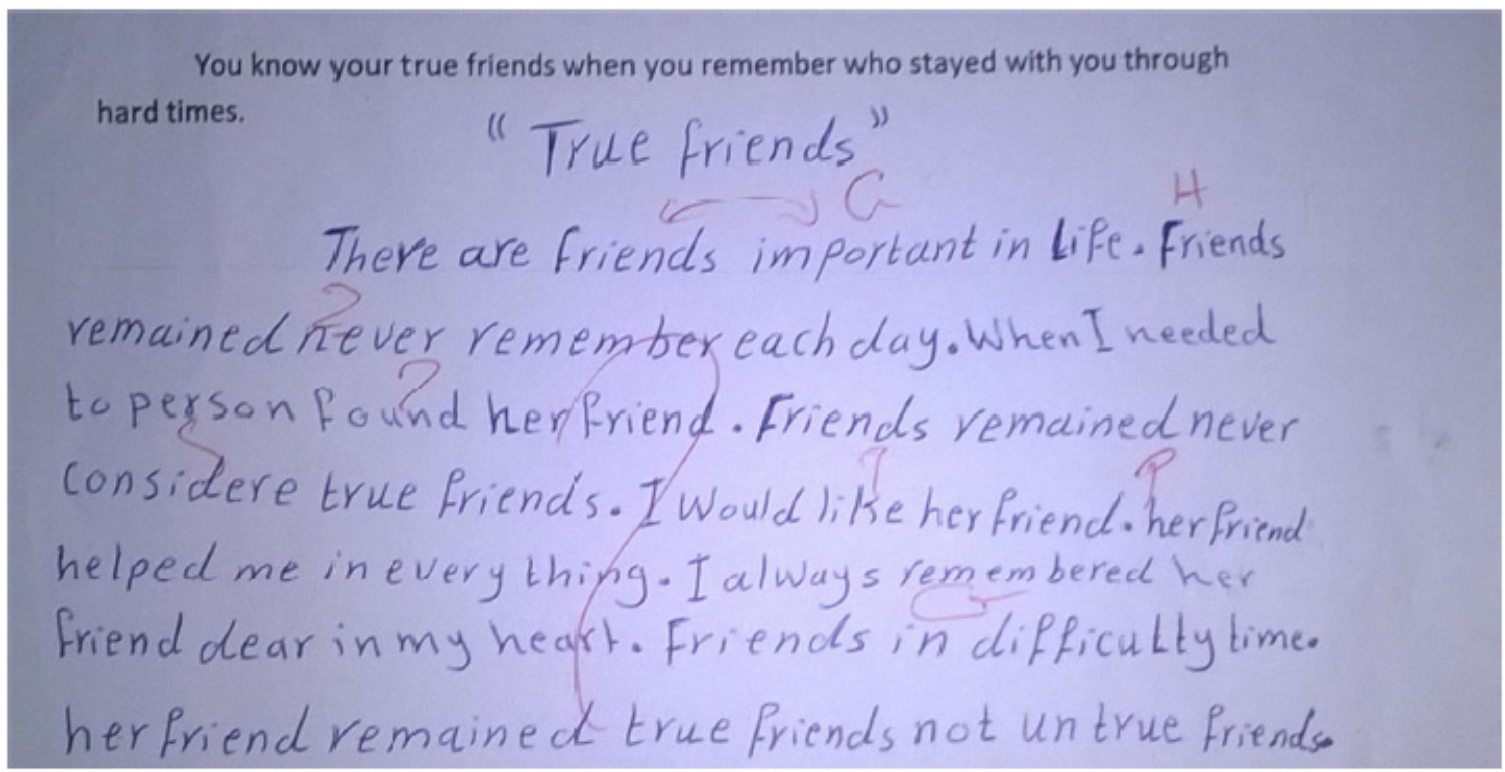


Test3. Three months later than the second one

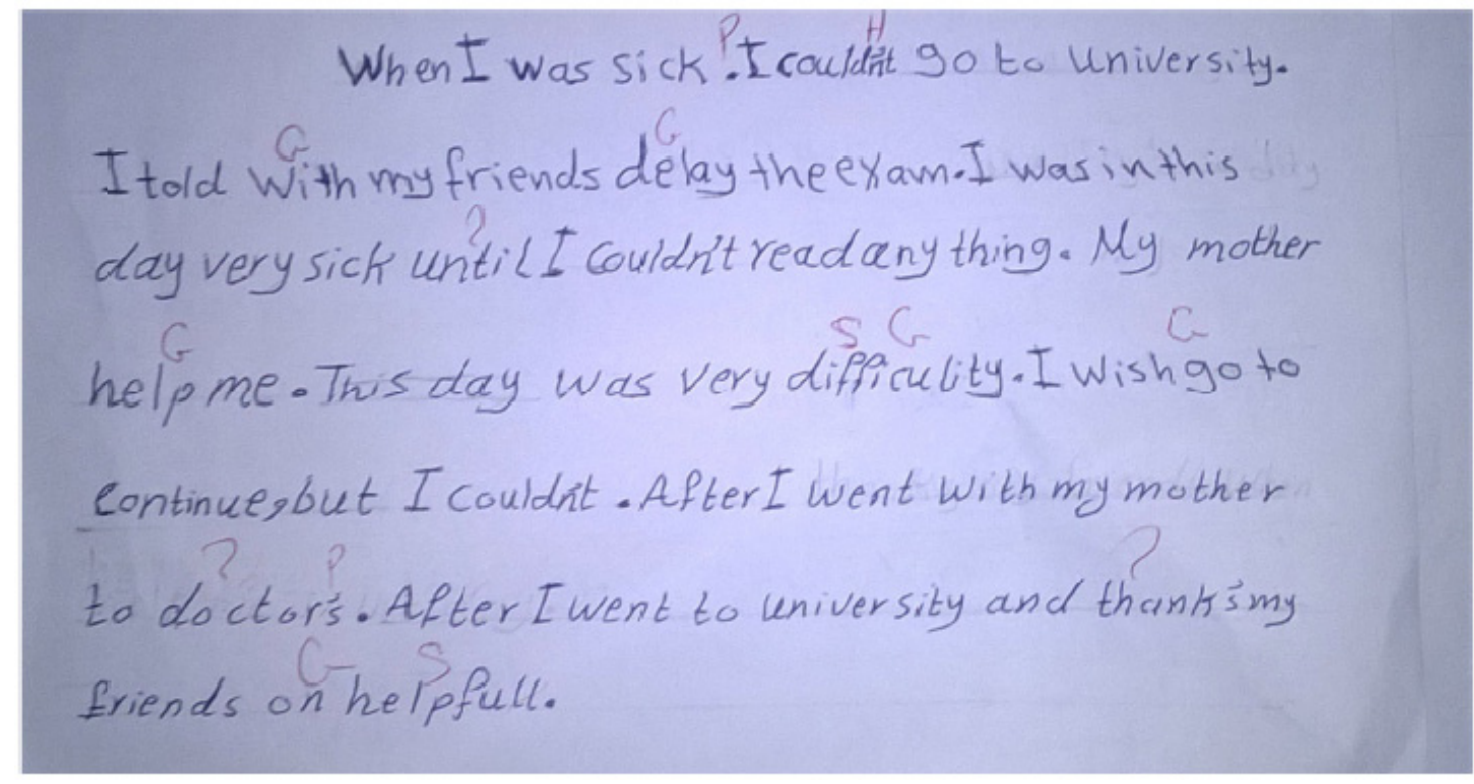

Appendix 2. Samples of another 2nd year university level student, English Department 2014-2015

Test1. After a month of introductory studying and training

Q2 Arrange the following words to write meaningful sentences with punctuation: (10 Marks)

1. pleașe/ yoú/ minute/ could/ me/, wait/ a/ for?

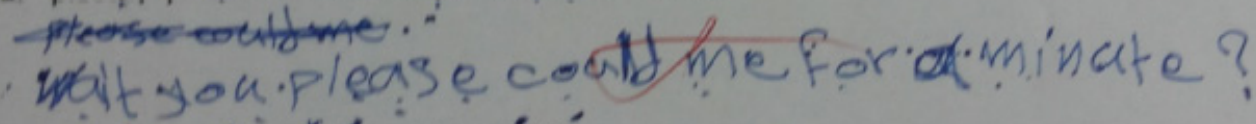

2. faŕ/go/ awáy/ thé/home/ don't/ from.

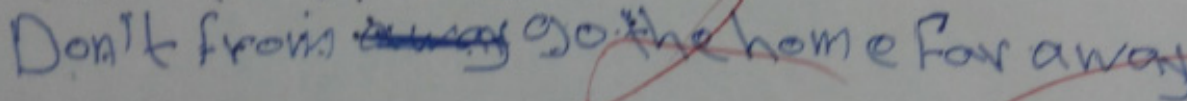

3. simple/ aré/ songs/ how/ théryl/

They asre semas yowisimple

4. a/ is/wearing/ child/ shirt/son/ red/ the/ my.

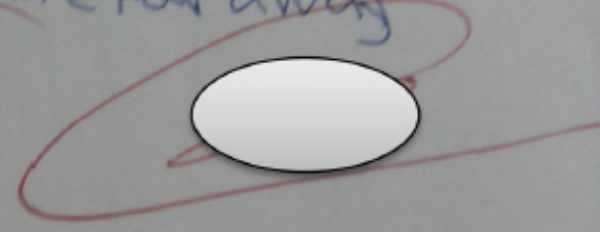

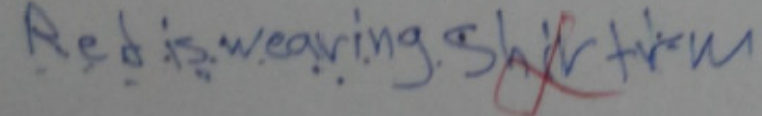


Test 2. Three months later than the first one

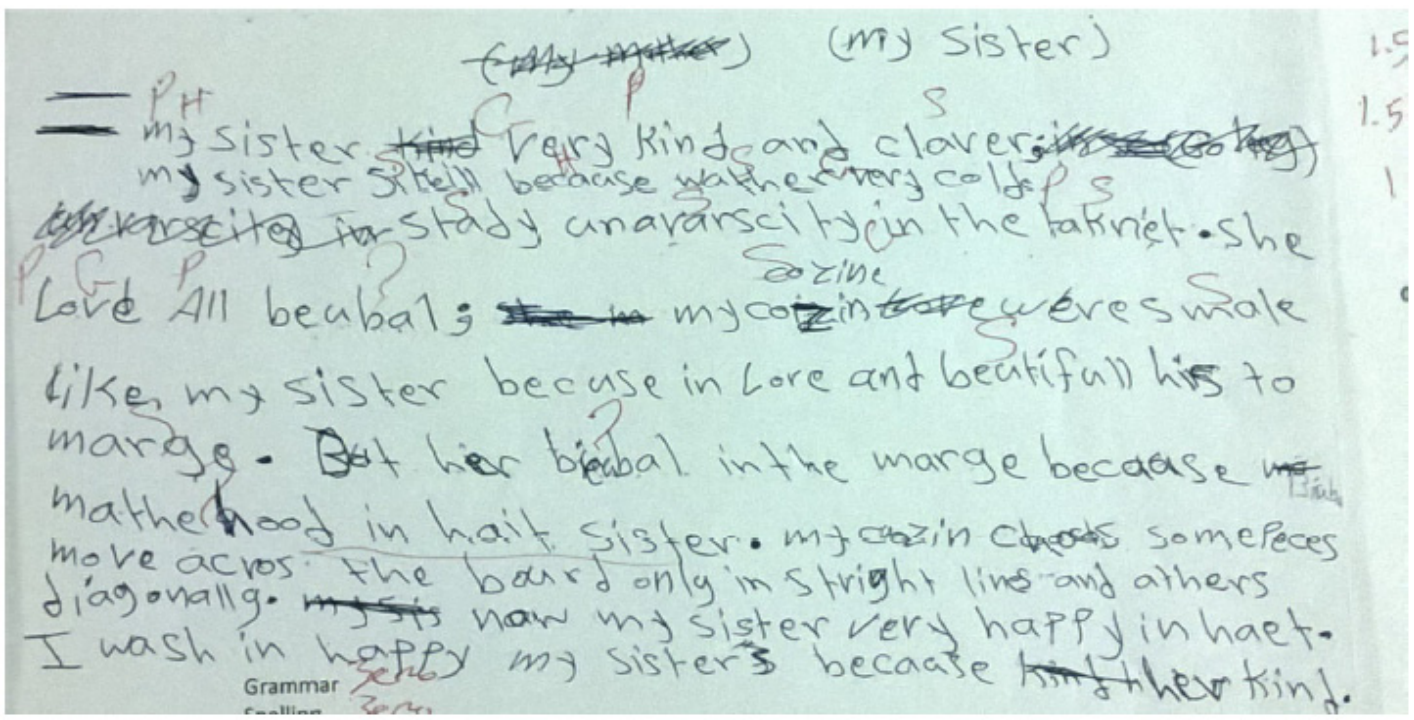

Test 3. Three months later than the second one

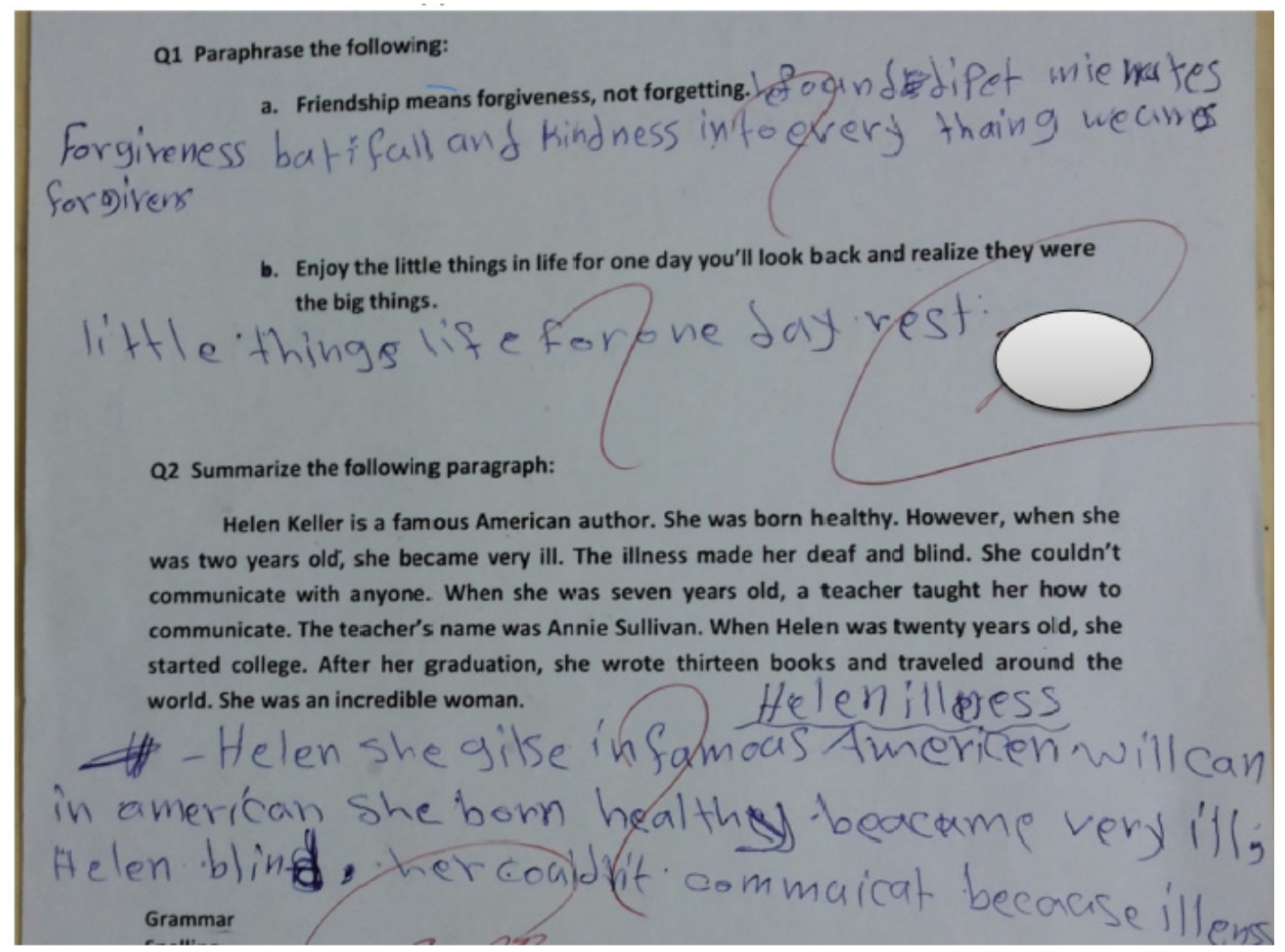

\section{Copyrights}

Copyright for this article is retained by the author(s), with first publication rights granted to the journal.

This is an open-access article distributed under the terms and conditions of the Creative Commons Attribution license (http://creativecommons.org/licenses/by/3.0/). 